\title{
DIFERENÇAS FISIOLÓGICAS ENTRE GENÓTIPOS DE MILHO DOCE (su-1) E MILHO COMUM DURANTE O DESENVOLVIMENTO
}

\section{PHYSIOLOGICAL DIFFERENCES BETWEEN SWEET CORN (SU-1) AND MAIZE DURING THE DEVELOPMENT}

\author{
Luiz Fernando Ganassali de OLIVEIRA JÚNIOR ${ }^{1}$ \\ Ricardo Enrique Bressan SMITH ${ }^{2}$ \\ Fabrício Oliveira REIS ${ }^{3}$ \\ Eliemar CAMPOSTRINI ${ }^{4}$ \\ Messias Gonzaga PEREIRA ${ }^{4}$
}

\begin{abstract}
RESUMO
Com o objetivo de verificar a influência de parâmetros fisiológicos das plantas de milho doce (H43IN) e milho comum (UENF506-8), nos períodos de desenvolvimento, nos teores de carboidratos e na produtividade desta espécie, foram conduzidos experimentos sob condições de campo, no Colégio Agrícola Antonio Sarlo, em Campos dos Goytacazes-RJ. Os experimentos foram instalados nos meses de setembro a janeiro de 2004. Os parametros fisiológicos foram estudados em quatro períodos: período III de crescimento vegetativo, V e VII reprodutivo e IX senescência da planta. Os parâmetros fisiológicos (taxa fotossintética líquida, déficit de pressão de vapor entre a folha e o ar e condutância estomática), observados, nas diferentes fases fenológicas, demonstraram haver diferenças significativas entre os dois genótipos. Os teores de açúcares e amido determinados nos estádios V e VII também demonstram diferenças, como esperado e a produtividade demonstrou superioridade do milho comum em relação ao milho doce.
\end{abstract}

Palavras chave: Zea mays L.; trocas gasosas; produtividade; teores de carboidratos.

\begin{abstract}
This work aimed to verify the influence of physiological characteristics of sweet corn (H43IN) and maize (UENF 506-8), at development stages, in carbohydrate contents and productivity in this species. These studies were conducted under field conditions at Colégio Agrícola Antonio Sarlo, in Campos dos Goytacazes-RJ. The experiments were developed from September to January / 2004. The physiological characteristics were investigated in four periods: period III of plant growth, V and VII reproductive and IX plant senescence. The physiological characteristics (net photosynthesis rate, leaf to air vapor pressure deficit, and stomatal conductance), observed during the different phenological cycles showed significant differences between the two genotypes. The sugar and starch contents determinated at stages $\mathrm{V}$ and VII also showed differences, as we expected, and the productivity in maize was higher than in sweet corn.
\end{abstract}

Key-words: Zea mays L.; gas exchanges; productivity; carbohydrate contents.

\footnotetext{
${ }^{1}$ Eng. Agr. Dr., Prof. Visitante do Departamento de Biologia, Universidade Federal do Espirito Santo. Av. Fernando Ferrari 514 - Campus Universitário - Goiabeiras, 29075-910, Vitória, ES. E-mail: Ifg@cchn.ufes.br. Autor para correspondência.

${ }^{2}$ Biólogo Dr.,Professor Associado da Universidade Estadual do Norte Fluminense Darcy Ribeiro, Laboratório de Melhoramento Genético Vegetal. Av. Alberto Lamego, 2000, Parque Califórnia, 28013-602, Campos dos Goytacazes, RJ. E-mail: bressan@uenf.br

${ }^{3}$ Eng. Agr. Dr. E-mail: fareoli@uenf.br

${ }^{4}$ Eng. Agr. Dr., Professor Associado Universidade Estadual do Norte Fluminense Darcy Ribeiro, Laboratório de Melhoramento Genético Vegetal. Av. Alberto Lamego, 2000, Parque Califórnia, 28013-620, Campos dos Goytacazes, RJ. E-mail: campost@uenf.br, messias@uenf.br
} 


\section{INTRODUÇÃO}

Em termos mundiais o milho é uma das culturas mais importantes em função de sua produtividade, composição química e valor nutritivo (FANCELLI e DOURADO NETO, 1996). O Brasil é um dos maiores produtores, tendo representatividade em todo território nacional, porém com a região Centro-Sul detendo cerca de $95 \%$ da produção (BULL, 1993). Em 2003 a cultura do milho apresentou aumento de $34 \%$ na produção, alcançando 48,3 milhões de toneladas de grãos produzidos, dos quais quase a metade $(24,1$ milhões de toneladas) foram colhidos na região Sul (IBGE, 2003). O elevado rendimento do país é devida à aptidão agrícola e multiplicidade de aplicações do milho, quer para a alimentação humana quer para a animal, assumindo relevante papel socioeconômico (FANCELLI e DOURADO NETO, 1996; TEIXEIRA et al., 2001). Além disso, o Brasil possui grande potencial para produção de milho doce, utilizado na forma enlatada, o qual é bastante apreciado pela população.

O milho doce é caracterizado por possuir pelo menos um dos oito genes mutantes que afetam a biossíntese de carboidratos no endosperma, sendo os principais: shrunken-2 (sh2) localizado no cromossomo 3, Brittle (bt) no cromossomo 5, sugary enhancer (se), sugary (su) e Brittle-2 (bt2), todos no cromossomo 4. Existem ainda o dull (du), no cromossomo 10, waxy (wx) no cromossomo 9, e amilose extender (ae), no cromossomo 5 . Tais genes podem atuar de forma simples ou em combinações duplas ou triplas (TRACY, 1994). Entretanto, associado a este gene, estão algumas características indesejáveis, como baixo rendimento e baixa resistência ao ataque de pragas e doenças por causa do maior teor de açúcares, quando comparado ao milho comum (TRACY, 1994).

Atualmente a cultura do milho tem alcançado altos níveis de rendimento. Essa evolução se deve aos crescentes estudos realizados em diversas áreas e, sobretudo, ao melhoramento genético, visando, por exemplo, maior produtividade e espigas maiores e bem granadas. Esses estudos também buscam melhoramentos nas características fisiológicas do milho, como maior taxa fotossintética líquida e condutância estomática.

O rendimento é influenciado por características morfológicas e fisiológicas da fonte (órgãos fotossintetizantes) e do dreno (órgãos consumidores dos metabólitos fotossintetizados, carboidratos principalmente). Toda produção de fitomassa depende da atividade fotossintética da fonte, porém a assimilação do $\mathrm{CO}_{2}$ é apenas um dos muitos fatores que influenciam o crescimento e desenvolvimento vegetal (FOYER e GALTIER, 1996). Desta forma, buscar mais informações sobre a fisiologia da fonte torna-se de fundamental importância, e uma forma muito utilizada para estudála é por meio de medidas de trocas gasosas (REIS, 2003).

Quantitativamente, o crescimento dos grãos pode ser avaliado em termos de capacidade da planta em suprir substrato para o crescimento (fonte) e do potencial dos grãos (dreno) em acumular substrato disponível (TOLLENAR, 1977). Foram identificadas duas fontes principais de substrato para 0 crescimento dos grãos: uma originada a partir da produção fotossintética após a antese e outra relacionada com a remobilização do material assimilado antes da antese e temporariamente armazenado, principalmente nos colmos. MACHADO et al. (1992) verificaram a remobilização tanto de carboidratos como de $\mathrm{N}$ a partir de órgãos vegetativos para os reprodutivos, principalmente durante 0 intenso enchimento da semente, sugerindo que, tanto a produção fotossintética como a atividade de absorção e assimilação de $\mathrm{N}$ foram insuficientes para atender a demanda da semente.

Embora os açúcares sejam produtos da fotossíntese, pouco se sabe sobre o controle da partição dos mesmos entre os diferentes órgãos da planta. Além disso, quando se considera as várias etapas de desenvolvimento da planta, a partição de açúcares torna-se extremamente dinâmica, pois novos órgãos surgem e se tornam importantes drenos energéticos. Dependendo do estágio de desenvolvimento, o grão constitui o principal dreno da planta, sendo assim, o presente trabalho objetivou comparar os genótipos de milho doce com o comum, avaliando alguns aspectos fisiológicos e de produtividade.

\section{MATERIAL E MÉTODOS}

O estudo foi realizado utilizando-se dois genótipos de milho, sendo um de milho comum (Uenf 506-8) e um de milho doce (H43IN). Os dois genótipos foram obtidos do programa de melhoramento genético de milho da UENF.

O gene mutante (su1) responsável pelo gosto doce e maciez no milho, foi transferido via cinco gerações de retrocruzamento a partir do genitor doador 43IN, para dois genitores recorrentes de milho comum (Cimmyt-8 e Piranão-8), encontrando-se no oitavo ciclo de seleção recorrente obtendo respectivamente os genótipos doce C43 e P43. Assim, a partir dos dois genótipos doce retrocruzados (C43 e P43), realizou-se o cruzamento obtendo-se o híbrido doce H43IN. O milho Uenf 506-8 é proveniente do cruzamento entre os genótipos recorrentes Cimmyt-8 e Piranão-8.

O ensaio experimental foi realizado durante a época de plantio de milho (setembro de 2003), utilizando delineamento em blocos ao acaso no Colégio Agrícola Antônio Sarlo, localizado em Campos dos Goytacazes no Norte do Estado do Rio

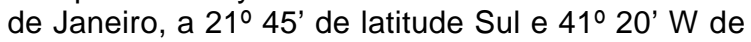
longitude e a $11 \mathrm{~m}$ de altitude (OLIVEIRA, 1996), classificado como tropical chuvoso, clima de bosque (Am) com uma precipitação média anual de 1023 $\mathrm{mm}$, evapotranspiração potencial de $1601 \mathrm{~mm}$ anuais e temperatura média anual de $23 \stackrel{\circ}{\circ}$ (OMETTO, 1981).

O delineamento experimental constou de dois blocos e a parcela experimental foi formada por quatro fileiras de 5,00 m de comprimento, espaçadas $1,00 \mathrm{~m}$ uma das outras, e $0,20 \mathrm{~m}$ entre plantas.

Os açúcares (glicose, frutose e sacarose) foram extraídos das sementes com etanol $80 \%$ a 70 ${ }^{\circ} \mathrm{C}$. A determinação de glicose, frutose e sacarose foi realizada por análise enzimática (STTIT et al., 1989) pela redução do $\mathrm{NAD}^{+}$a $340 \mathrm{~nm}$. Nos poços de uma placa de cultura de células, foram adicionadas à amostra, água e tampão (100 mM de Imidazole $\mathrm{pH}$ 7,4, $5 \mathrm{mM} \mathrm{MgCl}$, 2 mM NAD, $1 \mathrm{mM} \mathrm{ATP)}$ ), as quais foram adicionados $2 \mathrm{U}$ de $\mathrm{G}_{6} \mathrm{PDH}$ e $1,5 \mathrm{U}$ de 
hexoquinase para a mensuração da glicose. Após o término da reação, $3 U$ de fosfoglicose isomerase foram adicionadas ao meio para a determinação de frutose. A sacarose foi determinada adicionando $5 U$ de â-fructosidase após a determinação da frutose.

Após a extração dos açúcares solúveis, o amido foi extraído com $\mathrm{KOH} 0,2 \mathrm{~mol} \mathrm{~L}^{-1}$ a $95{ }^{\circ} \mathrm{C}$ e uma alíquota de $10 \mu \mathrm{L}$ foi retirada do extrato e, em seguida, foram adicionados $35 \mu \mathrm{L}$ de tampão citrato $\mathrm{pH} 4,6$ e $2 \mathrm{U}$ de amiloglicosidase, levando-se para incubação a $60{ }^{\circ} \mathrm{C}$ por $45 \mathrm{~min}$. Logo após, centrifugou-se a amostra a $13.600 \times \mathrm{g}$ por dois min, e uma alíquota de $5 \mu \mathrm{L}$ de glicose resultante dessa reação foi retirada e utilizada para a determinação de glicose, conforme descrito anteriormente.

As determinações de trocas gasosas foram realizadas com um sistema portátil de medições de trocas gasosas, IRGA, modelo LI-6200 (LI-COR,
Lincoln, NE, USA), em 4 plantas sempre na região mediana da quarta folha (contada de cima para baixo), completamente expandida, totalmente exposta à radiação solar, quando as plantas de milho se apresentavam em quatro estádios distintos de desenvolvimento: estádio III, desenvolvimento vegetativo (sexta semana após a emergência); estádio $\mathrm{V}$, inicio da polinização (nona semana após a emergência); estádio VII, grãos pastosos (22 dias após a polinização); estádio IX, grãos duros (48 dias após a polinização). As determinações da taxa fotossintética líquida $(A)$, condutância estomática $\left(g_{s}\right)$, fluxo de fótons fotossintéticos (FFF) e déficit de pressão de vapor entre a folha e 0 ar (DPV foram feitas às $08: 00 \mathrm{~h}$ e 12:00 $\mathrm{h}$ para comparação dos genótipos. A intensidade de radiação luminosa durante os estádios de desenvolvimento dos genótipos encontra-se na Tabela 1.

Tabela 1 - Fluxo de radiação incidente $\left(\mu \mathrm{mol} \mathrm{m} \mathrm{m}^{-2} \mathrm{~s}^{-1}\right)$ sobre as folhas de milho comum (Uenf506-8) e doce (H43IN), às 8:00 h e 12:00 h, durante os quatro períodos de desenvolvimento.

\begin{tabular}{|c|c|c|c|c|c|c|c|c|}
\hline \multirow{3}{*}{ Genótipos } & \multicolumn{4}{|c|}{ DFFF (8h) } & \multicolumn{4}{|c|}{ DFFF (12h) } \\
\hline & \multicolumn{8}{|c|}{ Estádio de desenvolvimento da planta } \\
\hline & III & $\mathrm{V}$ & VII & IX & III & $\mathrm{V}$ & VII & IX \\
\hline Uenf506-8 & $1093 \pm 61$ & $1697 \pm 21$ & $1514 \pm 130$ & $1593 \pm 18$ & $1382 \pm 71$ & $1544 \pm 162$ & $1786 \pm 48$ & $1726 \pm 82$ \\
\hline H43IN & $1112 \pm 36$ & $1764 \pm 4$ & $1750 \pm 17$ & $1587 \pm 19$ & $1408 \pm 116$ & $1338 \pm 164$ & $1639 \pm 95$ & $1754 \pm 62$ \\
\hline
\end{tabular}

\section{RESULTADOS E DISCUSSÃO}

A taxa fotossintética líquida $(A)$ determinada nos diferentes períodos de desenvolvimento dos dois genótipos de milho mostrou tendência semelhante de decréscimo ao longo dos estádios (Figura 1). No estádio III, a taxa fotossintética líquida foi superior aos demais, provavelmente para que o colmo armazenasse fotoassimilados suficientes para que na fase subseqüente o grão pudesse ter uma fonte de carbono adicional além da folha, ocorrendo assim a remobilização de carbono do colmo para o grão. Tal fenômeno não é incomum, pois MACHADO et al. (1992) já verificaram que durante o intenso enchimento da semente, a atividade fotossintética foi insuficiente para supri-la.

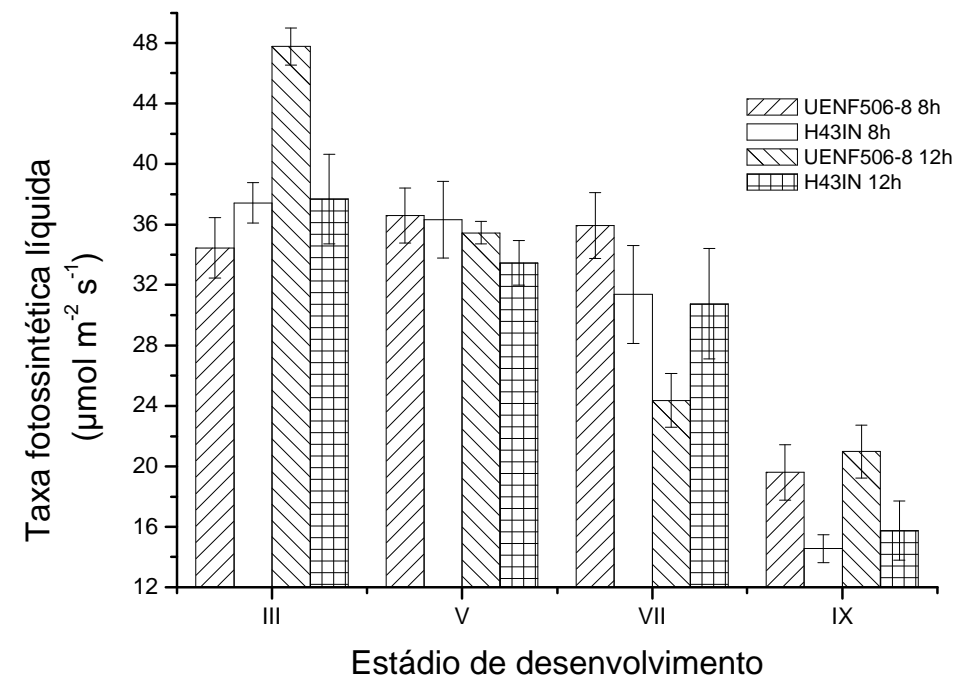

Figura 1 - Taxa fotossintética líquida $\left(\mu \mathrm{mol} \mathrm{m}^{-2} \mathrm{~s}^{-1}\right)$ em folhas de milho comum (Uenf 506-8) e doce (H43IN), durante o período de desenvolvimento. As barras indicam o erro padrão 
Em dias quentes, sem nuvens, com fluxo de fótons fotossintéticos (FFF) máximo ao meio-dia, a taxa fotossintética líquida e a condutância estomática de plantas de milho bem irrigadas no campo aumentam à medida que ao longo da manhã, atingindo seu valor máximo entre 9 e 10 horas da manhã, com decréscimo subseqüente a este período. Deste modo, pode-se dizer, que há uma "depressão da fotossíntese ao meio-dia" mesmo em plantas de milho irrigadas (HIRASAWA e HSIAO, 1999). A região onde se realizou o estudo se caracteriza por apresentar elevadas intensidades da radiação solar, o que está fortemente associada a elevadas temperaturas do ar $\left(T_{a r}\right)$ e da folha $\left(T_{f}\right)$ (REIS, 2007). Embora esta espécie esteja adaptada a regiões com elevadas temperaturas do ar, plantas irrigadas cultivadas em condição de campo normalmente apresentam murcha de folhas nos horários mais quentes do dia, normalmente observado das 11:00 h às 15:00 h (REIS e CAMPOSTRINI, 2005). Nos horários próximos ao meio dia, o processo de diminuição da taxa fotossintética líquida é conhecido como "depressão da fotossíntese ao meio-dia" (DFMD) e as causas desta redução em $A$ foi reportado por XU e SHEN (1997).

Nos estádios finais verificou-se menores taxas fotossintéticas em função da senescência das folhas (Figura 1). Verificou-se também as maiores diferenças entre os genótipos, no estádio VII às 12 $\mathrm{h}$, onde o milho Uenf 506-8 apresentou um forte decréscimo da taxa fotossintética líquida enquanto que o H43IN não diferiu das 8 h. Já no estádio IX os valores de fotossíntese não diferiram para nenhum dos genótipos entre horários. Contudo, a taxa fotossintética do H43IN foi inferior ao Uenf 506-8. A depressão da fotossíntese ao meio-dia, no entanto, foi menos pronunciada do que aquela observada em algumas outras espécies no campo como arroz (ISHIHARA e SAITO, 1987), soja (HUCK et al., 1983) e mamão (REIS, 2003).

Verificou-se que no estádio III, no qual está sendo definido o tamanho da espiga, número de grãos e máximo desenvolvimento do pendão, que o genótipo Uenf 506-8 não apresentou redução na condutância estomática às $12 \mathrm{~h}$ e ao mesmo tempo apresenta um pequeno incremento do $\mathrm{DPV}_{\text {folha-ar }}$ (Figura 2) reduzindo assim a taxa fotossintética líquida (Figura 1). Já o genótipo H43IN (milho doce) não foi tão eficiente quanto à taxa fotossintética líquida às $12 \mathrm{~h}$, em virtude da maior $\mathrm{DPV}_{\text {folha-ar }} \mathrm{e}$, conseqüentemente, menor condutância estomática; sugerindo assim, uma menor eficiência do genótipo H43IN neste estádio de desenvolvimento quando comparado ao Uenf506-8. Podendo ser justificado pelo milho doce apresentar menores espigas, menor números de grão e menor produtividade.

No estádio $V$, que representa o inicio da polinização, verificou-se que praticamente não houve variação nenhuma entre os genótipos, apenas uma menor taxa fotossintética líquida, condutância estomática e maior $\mathrm{DPV}_{\text {folha-ar }}$ para ambos os genótipos quando comparado ao estádio anterior (Figura 2). HIRASAWA e HSIAO (1999), também trabalhando com milho, observaram que, quando o DPV $V_{\text {folha-ar }}$ apresentaram valores menores em relação a outros dias de medida, a depressão da fotossíntese ao meio-dia não foi muito pronunciada. Esses resultados demonstram a possibilidade de altos

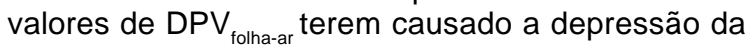
fotossíntese ao meio-dia e à tarde.

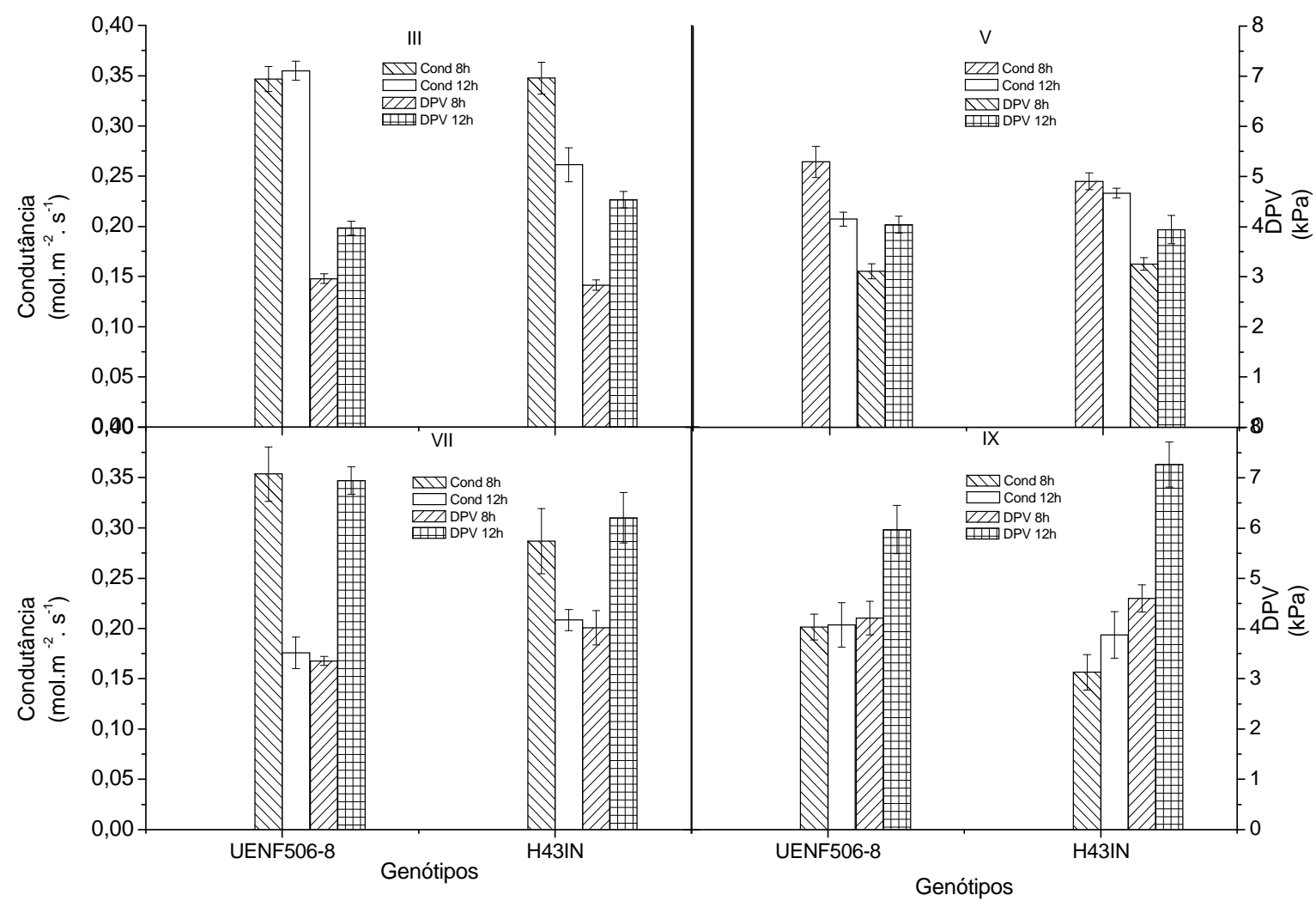

Figura 2 - Condutância estomática e Déficit de pressão de vapor entre a folha e o ar $\left(\mathrm{DPV}_{\text {folha-ar }}\right)$ em folhas de milho comum (Uenf506-8) e doce (H43IN), durante o período de desenvolvimento. As barras indicam os erros padrão. 
Verificou-se que no estádio VII, no qual os grãos encontram-se pastoso e as sementes desenvolvem-se rapidamente, às $8: 00 \mathrm{~h}$, a taxa fotossintética líquida, a condutância estomática e DPV $_{\text {folha-ar }}$ apresentaram valores semelhantes ao estádio lll para o genótipo Uenf506-8. Contudo, às 12:00 h a taxa fotossintética líquida sofreu um grande decréscimo em função de altos valores $\mathrm{DPV}_{\text {follha-ar }}$ que ocasionaram uma grande redução da condutância estomática para evitar o excesso de perda d'água. Provavelmente a remobilização de carbono a partir do colmo neste momento tenha suprido a deficiência da taxa fotossintética líquida. O genótipo H43IN manteve a mesma taxa fotossintética líquida nos dois horários, apresentando um incremento do $\mathrm{DPV}_{\text {folha-ar }}$ menor que do outro genótipo e conseqüentemente menor redução da condutância estomática.

No estádio IX, no qual os grãos encontravamse dentados, com queda na taxa de acumulação, acelerada perda de umidade da planta e as folhas senescendo. Assim, a taxa fotossintética líquida foi mínima para os dois genótipos com menores valores para as 12 h e para o genótipo H43IN, a condutância estomática praticamente manteve-se as mesmas nos dois horários e para os dois genótipos, o $\mathrm{DPV}_{\text {folha-ar }}$ foi superior para os dois genótipo às $12 \mathrm{~h}$ e maior para o genótipo H43IN.
A taxa fotossintética líquida, condutância estomática e déficit de pressão de vapor entre a folha e o ar observados nos dois genótipos e nos diferentes estádios de desenvolvimento do milho apresentaram diferenças muito peculiares entre o milho comum (Uenf506-8) e o milho doce (H43IN), possibilitando não somente, a diferenciação visual para algumas características como também por confirmação por meio das medidas das trocas gasosas.

No início do desenvolvimento dos grãos, estádio V, sejam eles mutantes su1 ou não mutantes, os teores de glicose e frutose são mais altos do que os teores de sacarose (Tabela 2). Durante o desenvolvimento das sementes, os teores de glicose e frutose decrescem, alcançando níveis muito inferiores aos encontrados no início. Ao contrário do que acontece com as hexoses, o teor de sacarose tende a aumentar ultrapassando o de hexoses, devido a biossíntese. Sendo no estádio VII onde encontramse os maiores teores de sacarose. Também no estádio VII, momento da colheita do milho para o consumo in natura, verificou-se a principal diferença entre o milho comum e o mutante. Com o milho comum apresentando um forte decréscimo de açúcares enquanto os mutantes mostraram um pequeno incremento de açúcar até o $30^{\circ}$ dia (dados não apresentados).

Tabela 2 - Teores de açúcares (glicose, frutose e sacarose) e amido determinados em sementes de milho comum (Uenf506-8) e doce (H43IN), nos estádios III e V de desenvolvimento e produtividade com palha e sem palha determinado no estádio V.

\begin{tabular}{|c|c|c|c|c|c|c|}
\hline \multirow{4}{*}{ Genótipos } & \multicolumn{6}{|c|}{ Açúcares } \\
\hline & \multicolumn{6}{|c|}{$\left(\mu \mathrm{mol} \mathrm{gMF}^{-1}\right)$} \\
\hline & \multicolumn{3}{|c|}{ V } & \multicolumn{3}{|c|}{ VII } \\
\hline & Gli & Fru & Sac & Gli & Fru & Sac \\
\hline Uenf506-8 & $570,58^{a}$ & $342,76^{a}$ & $196,88^{a}$ & $283,42^{a}$ & $250,72^{a}$ & $464,00^{a}$ \\
\hline \multirow[t]{5}{*}{ H43IN } & $696,92^{b}$ & $649,96^{b}$ & $137,79^{a}$ & $334,40^{\mathrm{a}}$ & $291,33^{b}$ & $727,85^{\mathrm{b}}$ \\
\hline & \multicolumn{3}{|c|}{ Amido } & \multicolumn{3}{|c|}{ Rendimento } \\
\hline & \multicolumn{3}{|c|}{$\left(\mathrm{mg} \mathrm{gMF}^{-1}\right)$} & \multicolumn{3}{|c|}{$\left(\mathrm{kg} \mathrm{ha}^{-1}\right)$} \\
\hline & V & \multicolumn{2}{|c|}{ VII } & VII & \multicolumn{2}{|r|}{ VII } \\
\hline & $\mathrm{Am}$ & \multicolumn{2}{|c|}{$\mathrm{Am}$} & c/palha & \multicolumn{2}{|r|}{ s/palha } \\
\hline Uenf506-8 & $74,20^{a}$ & \multicolumn{2}{|c|}{$305,83^{a}$} & $17.923^{a}$ & \multicolumn{2}{|r|}{$9.050^{\mathrm{a}}$} \\
\hline H43IN & $6,49^{b}$ & \multicolumn{2}{|c|}{$70,23^{b}$} & $14.405^{b}$ & \multicolumn{2}{|r|}{$7.835^{\mathrm{b}}$} \\
\hline
\end{tabular}

Os níveis de amido durante o desenvolvimento do endosperma estão presentes na Tabela 2, onde verificou-se incremento superior para o milho comum durante o desenvolvimento quando comparado ao milho doce.

O comportamento supracitado demonstrou a relação direta entre o maior acúmulo de açúcares e menor produção de amido pelo mutante. Tal comportamento pode ser atribuído à falta ou deficiência da enzima desramificadora de amido (WU et al., 2002). O menor acúmulo de amido é resultado de baixas taxas de biossíntese, provocados pela não expressão do gene SU-1 (Fig. 1), caracterizando a deficiência de uma ou duas enzimas desramificadoras de amido, as "DBEs" (isoamilase e pululanase). Tais enzimas são responsáveis pela transformação de fitoglicogênio em amilopectina, portanto, a sua falta acarreta maiores concentrações de açúcares (MYERS et al., 2000), refletindo diretamente no momento da colheita para o consumo in natura, onde verificou-se que, o rendimento do milho Uenf506-8 foi superior a do milho H43IN. Desta forma, verificou-se a principal diferença entre milho doce e milho comum, onde a deficiência de enzimas durante o metabolismo de carboidrato acarreta na maior concentração de açúcares e menor rendimento. 


\section{CONCLUSÕES}

1 - O maior acúmulo de açúcares nos grãos afeta diretamente a biossíntese de amido, reduzindo drasticamente sua concentração no mutante su-1. 2 - A biossíntese de amido no milho sugere estar relacionada com o maior acúmulo de matéria fresca e conseqüentemente com a produção.
3 - O milho comum apresenta maior eficiência fotossintética quando comparado ao milho doce no estádio de desenvolvimento em que é definido a magnitude da espiga e a produtividade.

\section{REFERÊNCIAS}

1. BUIL, L.T. Cultura do milho: fatores que afetam a produtividade. Piracicaba: Potafos, 1993. $301 \mathrm{p}$.

2. FANCELLI, A.L.; DOURADO NETO, D. Milho: fisiologia da produção. In: SEMINÁRIO SOBRE FISIOLOGIADA PRODUÇÃO E MANEJO DE ÁGUA E DE NUTRIENTES NA CULTURA DO MILHO DE ALTA PRODUTIVIDADE, 1996, Piracicaba. Anais. Piracicaba: ESALQ/USP-POTAFÓS, 1996. p. 1-29.

3. FOYER, C.H.; GALTIER, N. Source-sink interaction and communication in leaves. In: ZAMSKI, E; SCHAFFER, A.A. (Eds.) Photoassimilate distribution in plants and crops. Source-sink relationships. New York, 1996. p. 331-340.

4. HIRASAWA, T.; HSIAO, T.C. Some characteristics of reduced leaf photosynthesis at midday in maize growing in the field. Field Crop Research, v. 62, n. 1, p. 53-62, 1999

5. HUCK, M.G.; ISHIHARA, K.; PETERSON, C.M.; USHIJIMA, T. Soybean adaptation to water stress at selected stages of grow. Plant Physiology, v. 73, n. 1, p. 422-427, 1983.

6. IBGE. Municipal agricultural production - 2003. Disponível em: http://www.ibge.gov.br/english/presidencia/noticias/ noticia_visualiza.php?id_noticia=259\&id_pagina=1. Acesso em 3 de março de 2005.

7. ISHIHARA, K.; SAITO, K. Diurnal course of photosynthesis, transpiration and diffusive conductance in the single leaf of the rice plants growing in the paddy field under submerged conditions. Japanese Journal of Crop Science, v. 56, n. 1, p. 8-17, 1987.

8. MACHADO, E.C.; SILVEIRA, J.A.G.; VITORELLO, V.A.; RODRIGUES, J.L.M. Fotossíntese, remobilização de reservas e crescimento de grãos em dois híbridos sob deficiência hídrica na fase de enchimento de grãos. Bragantia, Campinas, v. 51, n. 12, p. 151-159, 1992.

9. MYERS A.M; MORELL M.K.; JAMES M.G.; BALL S.G. Recent progress toward understanding biosynthesis of the amylopectin crystal. Plant Physiology, v. 122, n. 1, p. 989-997, 2000.

10. OLIVEIRA, V.P.S. Avaliação do sistema de irrigação por sulco da fazenda do alto em Campos dos Goytacazes- RJ. Campos dos Goytacazes, 1996. 82 f. Dissertação (Mestrado) - Universidade Estadual do Norte Fluminense.

11. OMETTO, J.C. Bioclimatologia tropical. São Paulo: Agronômica Ceres, 1981. p. 390-398.

12. REIS, F.O. Trocas gasosas, eficiência fotoquímica e fluxo de seiva xilemática em mamoeiro do grupo Formosa cultivado em condição de campo na regiã o norte fluminense. Campos dos Goytacazes, 2003. 94 f. Dissertação (Mestrado) - Universidade Estadual do Norte Fluminense.

13. REIS, F.O.; CAMPOSTRINI, E. Otimização das trocas gasosas ao meio dia, por meio da aplicação de água via microaspersão sobre o dossel do mamoeiro. SIMPÓSIO DO PAPAYA BRASILEIRO, 2., Vitória, 2005. Anais. Vitória: INCAPER, 2005. p. 385-389.

14. REIS, F.O. Microaspersão sobre copa em mamoeiro 'Golden': um estudo relacionado às trocas gasosas, á eficiência fotoquímica e ao fluxo de seiva xilemática. Campos dos Goytacazes, 2007. 93 f. Tese (Doutorado em Produção Vegetal) - Universidade Estadual do Norte Fluminense.

15. STITT M.; LILLEY R.M.C.; GERHARDT R.; HELDT H.W. Metabolite levels in specific cells and subcellular compartments of plant leaves. Methods Enzymol, v. 174, n. 1, p. 518-552, 1989.

16. TEIXEIRA, F.F.; SOUSA, I.R.P.; GAMA, E.E.G.; PACHECO, C.A.P.; PARENTONI, S.N.; SANTOS, M.X.; MEIRELLES, W.F. Avaliação da capacidade de combinação entre linhagens de milho doce. Ciência e Agrotecnologia, v. 25, n. 3, p. 483-488, 2001.

17. TOLLENARR, M. Sink-source relationships during reprodutive development in maize: Review Maydica, v. 22, n. 2, p. 49-75, 1977.

18. TRACY, W.F. Sweet corn. In: HALLAUER, A. R. (Ed.) Specialty corns. New York: CRC Press, 1994. p.147-187.

19. WU, C.; COLLEONI, C.; MYERS, A. JAMES, M. G. Enzymatic properties and regulation of ZPU1, the maize pullulanase-type starch debranching enzyme. Archives of Biochemistry and Biophysics, v. 406, n. 1, p. 21-32, 2002.

20. XU, D.Q.; SHEN Y. Midday depression of photosynthesis. In: PESSARAKLI, M. (Ed.) Handbook of photosynthesis. New York: Marcel Dekker, 1997. p. 451-459.

Recebido em 27/10/2006 Aceito em 20/08/2007 